v.23, n.1, Especial do IV Simpósio de Nutrição de Animais de Companhia, p.03-04, 2018

\title{
EFEITO DE DIFERENTES REATORES DE PLASMA NÃO TÉRMICO NA DESCONTAMINAÇÃO FÚNGICA EM RAÇÃO EXTRUSADA PARA CÃES NATURALMENTE CONTAMINADAS
}

(Effect of different non-thermal plasma reactors on fungal decontamination in extruded food for naturally contaminated dogs)

Juliana R. da Silva ${ }^{1}$, Anelise L.V. Cubas², Elisa H.S. Moecke², Vildes M. Scussel ${ }^{1}$

\begin{abstract}
'Laboratório de Micotoxinas e Contaminantes Alimentares, Universidade Federal de Santa Catarina, Florianópolis, SC.

¿Laboratório de Engenharia Ambiental Sanitária, Universidade do Sul de Santa Catarina, Palhoça, SC. E-mail: jusilva.zootecnista@gmail.com
\end{abstract}

Resumo: Foi analisado o efeito de diferentes reatores de plasma não térmico (PNT) na descontaminação fúngica em ração extrusada para cães. Foram analisados alimentos comerciais extrusados para cães contaminados naturalmente. As amostras foram divididas em 4 grupos para o estudo do efeito PNT. Três grupos de tratamento (um para cada reator) e um grupo controle (sem PNT). As amostras passaram por 10 min de tratamento a uma tensão de $4,5 \mathrm{Kv}$ em corrente alternada. Após 7 dias de incubação não foram observados crescimento fúngico nas rações tratadas, independentemente do tipo de reator. O plasma não térmico é capaz de inativar fungos em rações extrusadas para cães naturalmente contaminadas. Os três tipos de reatores foram eficazes para a descontaminação desse alimento.

Palavras-chave: fungos; inativação; segurança

Abstract: The effect of different non-thermal plasma reactors (NTP) on fungal decontamination in extruded dog food was analyzed. Commercial extruded foods were analyzed for naturally contaminated dogs. The samples were divided into four groups for the study of the NTP effect. Three treatment groups (one for each reactor) and one control group (without NTP). Samples underwent 10 min of treatment at a voltage of $4.5 \mathrm{kv}$ in alternating current. After 7 days of incubation no fungal growth was observed in the treated rations, regardless of the type of reactor. Non-thermal plasma is able to inactivate fungi in extruded diets for naturally contaminated dogs. The three types of reactors were effective for the decontamination of this food.

Keywords: fungi; inactivation; safety

Introdução: Com ampla gama de produtos no mercado, proprietários passaram a não somente se interessar pelos níveis nutricionais das rações, como também pela sua segurança. A falta de segurança pode acarretar prejuízos para os fabricantes e para a saúde dos animais, um dos fatores de risco se refere à contaminação do alimento por fungos. Essa contaminação pode ocorrer desde a produção e o armazenamento da matéria-prima, principalmente grãos, que são amplamente utilizados na fabricação de rações para cães, até a industrialização e embalagem do produto final (Scussel, 2017).

Em relação à descontaminação de fungos, muitos estudos já foram realizados utilizando o plasma não térmico (PNT) como descontaminante (Dasan et al., 2016), no entanto não foram encontrados na literatura trabalhos utilizando PNT em alimentos para cães. Assim, o objetivo do trabalho foi avaliar a descontaminação fúngica em ração extrusada para cães naturalmente contaminada utilizando três tipos de reatores de PNT. 
Material e Métodos: Foram analisados alimentos comerciais extrusados para cães contaminados naturalmente. As amostras foram divididas em quatro grupos para o estudo do efeito PNT. Três grupos de tratamento (um para cada reator) e um grupo controle (sem PNT). Os reatores foram do tipo: caneta (I), ponta plano único (II) e ponta plano tipo chuveiro (III). As amostras passaram por 10 min de tratamento. $\mathrm{O}$ sistema elétrico utilizado consistiu de uma fonte de alimentação de $17 \mathrm{kV}$ e um variac para ajustes de tensão de entrada para $4,5 \mathrm{kV}$.

Para a geração de plasma, foi utilizada corrente alternada com entrada de ar atmosférico. Foram realizadas 2 repetições de cada tratamento. Posteriormente aos tratamentos, as placas de Petri, com meio de cultura PDA, foram colocadas em estufa a $25^{\circ} \mathrm{C}$. Após 7 dias, as placas foram analisadas para presença de fungos.

Resultados e Discussão: Foi observado que o PNT foi eficiente para reduzir esporos de fungos em rações extrusadas naturalmente contaminadas (Figura 1). A avaliação da carga de fúngica tem sido um bom indicador das condições sanitárias de alimentos comerciais para cães. Os danos causados por fungos estão geralmente relacionados com perdas nutricionais de matérias-primas e deterioração dos produtos finais, além de afetar a saúde animal (Girio et al., 2012).

O PNT apresenta tratamento uniforme, pode executar a atividade a baixa temperatura e sem alteração de sabor, odor e estrutura do alimento, além de não deixar resíduos (Niemira, 2012).

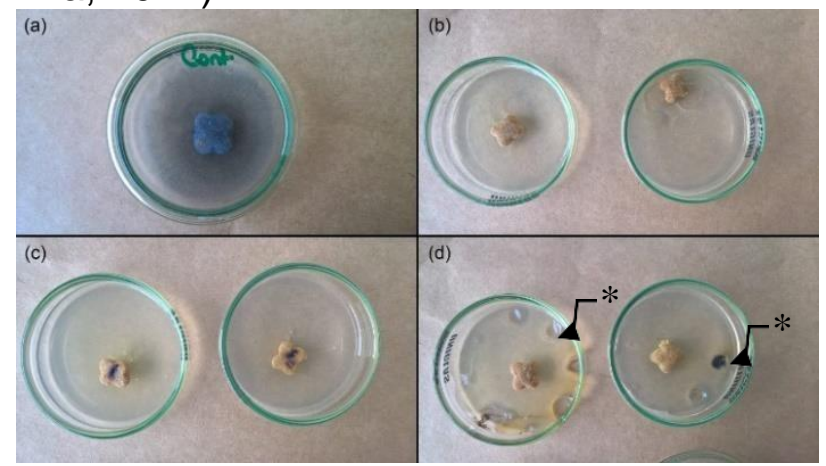

Figura 1. Crescimento de colônia fúngica em placa de Petri contendo meio de cultura PDA após 7 dias de incubação posterior ao tratamento com 3 diferentes tipos de reator de plasma não térmico: (a) controle; (b) reator tipo caneta; (c) reator tipo ponta plano único e (d) reator tipo chuveiro $\left(^{*}\right)$ indicam halos formados por descarga.

Conclusão: O plasma não térmico é capaz de inativar fungos em rações extrusadas para cães naturalmente contaminadas. Os três tipos de reatores foram eficazes para a descontaminação desse alimento.

Referências: DASAN, B.G., MUTLU, M., BOYACI, I.H. Decontamination of Aspergillus flavus and Aspergillus parasiticus spores on hazelnuts via atmospheric pressure fluidized bed plasma reactor. International Journal of Food Microbiology, p.50-59, 2016.

GIRIO, T.M.S et al. Qualidade microbiológica de rações para cães comercializadas no varejo em embalagem fechada e a granel. Ars Veterinaria, 28:p.36-40, 2012, NIEMIRA, B.A. Cold plasma decontamination of foods. Annual Review of Food Science and Technology, 3: p.125-142, 2012.

SCUSSEL, V.M. "Fungos em Grãos Armazenados." Armazenagem de grãos, Campinas: Biogeneziz, 2017. 